\title{
LEV SERGEEVICH YAGUZHINSKII To the 75th anniversary
}

DOI: $10.1134 / \mathrm{S} 1990747810030128$

On April 15, 2010, Professor Lev Sergeevich Yaguzhinskii reached the age of 75. Lev Sergeevich undoubtedly is one of the brightest figures in physicochemical biology. The breadth of its scientific interests, encyclopedic knowledge in various areas of physico-chemical biology, analytical mentality, ability to seize the basic essence of a considered problem and generate new original ideas - all this characterizes him as an extraordinary person.

Charm and scale of this scientist form a sort of gravity centre. Yaguzhinskii is known, respected and loved not only in Moscow, in Belozersky Institute of Physico-chemical Biology, where he has been working together with his opponent and friend, Academician V.P. Skulachev. A lot of scientist in our country and abroad constantly address him and get his consulting help and an expert estimation. The variety of research subjects and originality of ideas and approaches invariably attract youth, and Yaguzhinskii's laboratory is full all day long till late evening. More than 50 scientists carried out their $\mathrm{PhD}$ research under his supervision.

There are several directions in physico-chemical biology, where the works of Lev Yaguzhinskii have brought the most appreciable contribution. One of the main directions concerns the coupling mechanism of oxidation and oxidative phosphorylation in mitochondria and chloroplasts. Consistently, using different systems, Yaguzhinskii with his colleagues and pupils has been substantiating an essential role of a barrier for the proton transfer from the membrane surface to the aqueous phase. This direction remains very important today, as is proved by numerous publications on functioning bioenergetic systems, in which a localized energized proton allows energy accumulation by direct coupling with ATP-synthase complex. His works also considerably developed the concepts on the action mechanisms of inhibitors, ionophores, and uncouplers in biological membranes. Of particular importance is the detection in mitochondrial NADH- dehydrogenase of sites of nonspecific inhibition by hydrophobic substances.

Before his studies in bioenergetics, Lev Yaguzhinskii was involved in research in oncology. He studied the action mechanisms of anti-tumor alkylating substances on the system of cell membrane energetics upon their interaction with mitochondria. In these works an ability of alkylating agents was shown to cause lipid peroxidation and to induce nonspecific permeability of the internal mitochondrial membranes, which, in turn, is one of the key stages of apoptosis. Simultaneously Yaguzhinskii studied the mechanism of action of tumor promotors and found out two binding patterns of the phorbol esters on the active center of proteinkinase $\mathrm{C}$, an enzyme playing a key role in tumor promotion.

It is difficult to capture all scientific interests and results of Lev Sergeevich Yaguzhinskii and his numerous significant works in various scientific directions. In recent years he attended to environmental problems and firstly to the problem of protection of natural water from the pollution by man-made products. Yaguzhinskii has formulated an original concept of external toxicity of various substances as a result of infringement of homeostasis of reactive oxygen species that play a signaling and regulatory role in live processes in humans and animals.

Lev Sergeevich Yaguzhinskii is a bright example of self-denying service to Science. His colleagues, friends and pupils wish him creative longevity, good health and happiness.

Yu.A. Antonenko

V.I. Bruskov

Editorial board of the journal Biologicheskie membrany joins these greetings. Lev Yaguzhinskii has been a member of the Editorial for many years and it is difficult to overestimate his personal contribution to the maintenance of prestige of our journal.

S.S. Kolesnikov 